\title{
Cultural objects in Ingarden's realism. In honour of the 50th anniversary of Ingarden's death
}

\author{
PATRICIA LIMIDO \\ Université de Paris - Paris Diderot \\ $\triangle$ patricia.limido@parisdescartes.fr
}

\begin{abstract}
The purpose of this article is to examine the type(s) of realism that Ingarden builds by analysing the place of man in nature and the production of intentional and cultural objects. The possibility of creating cultural worlds raises the problem of the conditions of possibility of an interaction between the intentional order of cultural products and the real order of connections of natural things. Ingarden's positions are rather ambiguous, so I will try to study in what sense we can speak of realism, naturalism or idealism. And since the ontological analysis that Ingarden follows excludes the possibility of an intertwining between the different domains of being, I will hypothesize an idea of emergence in order to think an articulation between the cultural worlds of man and the factual world of nature. This approach will be guided by the status of intentional and cultural objects and that of aesthetic qualities and values which involve the notion of Gestalt. The challenge is to understand how new things, values and qualities can fit into the order of the real world. On the one hand, this allows to unveil the complexity and innovation of Ingarden's analyses on the interactions between natural and ecological systems. And on the other hand, to realize the great unity of his philosophy because the different themes, ontology and aesthetics, axiology and epistemology continuously interplay together.
\end{abstract}

Keywords Ingarden, realism, culture, values, Gestalt. 
Ingarden's opposition to Husserl, after the transcendental shift of Ideen $\mathrm{I}$, is well known and concerns the ontological status of the real world and its relationship to consciousness. We remember that his critical work begins with the analysis of intentional objects, mainly artistic objects. So I would try to examine the type(s) of realism that Ingarden builds by analysing the place of man in nature and its strange ability to produce new cultural objects. The possibility of creating cultural worlds raises the problem of the conditions of possibility of an interaction between the intentional order of cultural products and the real order of connections of natural things. The challenge is to understand how new things (buildings, works of art, games, laws, etc., and also values, sense and qualities) can fit in the real natural world. Indeed, since the ontological analysis excludes the possibility of a causal intertwining between the different domains of being, I will hypothesize an idea of emergence in order to think an articulation between the cultural worlds of men and the factual world of nature. So, we could define Ingarden's claim of realism as a thought of the border, as the will to think about human life both in the objectivity of the real world and in the objectivity of a cultural world endowed with values.

\section{Intentional object, between constitution and reality}

Ingarden's first concern is the ontological difference between two modes of being, that of consciousness and that of the real external world. The real world is a multiplicity of self-subsistent individual things; these things are of natural and material kind and the causal relation is a basis of the unity of the real world. In the real world, some cultural worlds reach to appear and subsist. They offer special objects (like buildings, tools, music or paintings, money, flag, university, and so on,) which have been produced by human activity and that Ingarden calls intentional objects.

In this context, he analyses these specific objects by focusing on the most typical of them, such as the works of art, which he sees as prototypes of intentional objects. An intentional object, like Faust, is a heteronomous object, dependent on the acts of consciousness that created it, and which, as such, contain nothing more than what it has been endowed with by the acts that created them. And because these acts are limited in number, their products present places of indeterminacy (Unbestimmtheitsstellen), i.e., they are not totally and nor in every respect determined in their being and their being-so. This limited character attests to their ontological difference with real things.

Conversely, because the real things are given in an always renewed perception by sketches, it shows for Ingarden that sketches are an indication of 
the autonomy of the reality that always escapes, always offers new determinations that can confirm or contradict our expectations, because the things have a rich identity, a constitutive nature that is their own, and all their properties are immanent. In other words, the fact that a thing is always given through sketches militates in favour of an autonomous being independent of consciousness, who may exist without being perceived because it exists in itself in a complete and completely determined manner, while the intentional object exists only by virtue of a finite number of determinations conferred by the acts of consciousness. Finally, the real thing offers a transcendence defined in a strong sense, that is exteriority and independence from consciousness, and not only the simple intentional transcendence of the noematic sense. This is the first feature of Ingardenian realism: the exteriority and the consistency or resistance of things, that he calls transcendence $1(1918,11)$.

In contrast, the analysis of works of art, as products of intentional acts, therefore serves as an entry point into the Idealism-Realism controversy, and more particularly into the question of the constitution of objects, whatever they may be. Works of art, like all cultural objects (artefacts and machines, sciences and social institutions), are the result (Gebilde) of a series of more or less complex creative acts and their analysis should make it possible to clarify the processes of constitution. In this respect, a distinction must be made between the processes of constitution of these cultural objects and the processes of constitution of intentional meanings.

For Ingarden, there are two types of products and two types of constitutive activity $(2016,197)$. On the one hand, the purely intentional objects created by the fantasy (or free creativity) of consciousness, and here Ingarden speaks rather of creation or construction than constitution. On the other hand, there are objects that are only intentional. Only intentional that means that a thing, which exists in itself, may be intended by intentional acts of meaning (Meinen), but it doesn't belong to its nature to be so intended. In this sense, all the real objects can be grasped by acts of intentional meaning (perceptive or cognitive), but they are not created at all, they are self-subsistent autonomous things. That means too that the intentional meaning is powerless, "he leaves the encountered object entirely undisturbed" $(2016,196)$. Nevertheless, all the intending acts, that don't do anything real to the perceived objects, have a new kind of efficacy: "the efficacy of forming (Bildung) the intentional objects" $(2016,197)$. First of all, it concerns the "intentional perceptual object", and what Ingarden calls intentional object here corresponds more to the Husserlian noema and designates the sense of the perceived (the sense through which a thing is intended and perceived). In this context, perceptual acts are not creative in the same sense as fantasy, because they constitute entities that have to 
reproduce and "make them fit the radically transcendent objects given in these acts" in such a way they achieve coincidence with them, and become somewhat transparent $(2016,202)$.

This is the privileged acceptation of the constitution for Ingarden: to constitute the sense or the meaning of objects or phenomena through which things appear to us, as they are actually. This interpretation is also in line with the definition proposed by Walter Biemel, one of Husserl's closest commentators. He establishes that for Husserl since the Lessons of 1907, "to constitute" most often refers to "the act of making an object perceptible", that is, "the act of coming to meet the being, in a way that this being can be announced" (Husserl 1959, 46). It is therefore almost literally that Ingarden considers the noema, the constituted intentional object, as a kind of mediator between the thing and the consciousness, a mediator whose epistemological legitimacy lies precisely in its ability to adapt to the thing as clothes, which both veil and reveal it. So, the sense of objects, through which things appear to us, can be constituted in a legitimate way or in an illegitimate way, i.e. with properties that may or may not be in conformity with the nature of things. This is why constitutive analysis consists in descending from the meanings of constituted objects to the ultimate data that are their source, to see how the meanings are constituted, and whether they have been constituted according to a legitimate knowledge.

These constitutive analyses are essential for Ingarden and for the controversy, because he hopes that in the examination of the deeper and deeper layers of the experiences and their correlates, "the last original elements, those which are no longer constituted" $(1918,15)$, could be reached and that the consciousness would discover them in the sensation. The ideal epistemological situation (the most favourable to the realistic option) would consist in finding ultimate data that bear the mark of a real exteriority or the signature of their belonging to another sphere. This would be ideal because it would reveal that the behaviour of the ego is essentially receptive and adaptive, and not productive-creative in a strong sense (and that is why the intentional object would be transparent just as an intentional duplicate of the real object). In other words, there would then be evidence, pleading for a realistic approach. This would be a perfect and optimistic way to resolve the controversy through an ontological analysis approach. Conversely, it could be confirmed that a constitution in which the subject has completely determined the aspects and properties of an object produces purely intentional objects resulting from creative fantasy, that means from an activity whose regime is imaginative, playful or strictly inventive, without being motivated by prescriptions resulting from the very things. 


\section{Two kinds of constitution, two kinds of object}

This is why it is imperative to understand how noemata are constituted, because it would also make it possible to understand the clear difference between these two kinds of intentional products as a result of the two kinds of constitution: objects resulting from fantasy, and perceptual or cognitive senses derived from processes which are more objective and tend to be adequate to reality.

This leads to two remarks. First, these two kinds of constitution reinforce in all cases the fact that there must be something to which the subject adapts and conforms, or from which he separates, moves away to invent other new figures. This always militates in favour of realism, understood as transcendent exteriority. But, in second time, it should be noted, with some surprise, that Ingarden acknowledges with Husserl the validity of a certain epistemological idealism, since what we can know about the world is inevitably constituted by the consciousness that constitutes the senses of objects (noema). And this fundamental agreement is reflected in a very peculiar remark:

There is no idealism in affirming that phenomena, revealing certain objects and constituted in certain processes of cognitive acts, are dependent on the intentions contained in these acts and in their synthetic connections. $(1963,313)$.

There is no idealism, Ingarden says in 1963, in recognizing that we access things only through the medium of meanings or aspects constructed by consciousness. Let us remember for the moment that this dual approach of production/constitution allows the realization of new objects, and indeed multiple domains of objects that form every cultural world.

From the imaginary game of guessing shapes in the clouds, to the creation of the most advanced social institutions, via works of art, technical objects or models, Ingarden considers different degrees of inventive construction, all of which share the same creative abilities of consciousness. The most fundamental difference ultimately lies in the ability of these creations to be embodied and to be shared, to have, as Ingarden says, a "fundamentum in re". To be embodied, that means that these representations succeed in including themselves into a material, in dealing with natural and physical processes, in transforming materials to the point of becoming the place of expression of a meaning or a value $(2016,201)$. Thus, a sculpture, a combine harvester or a university are intentional intersubjective products, manifesting the capacity of consciousness to produce not only something that did not exist, but even more an entity that takes shape in a real foundation, settles in a sustainable way and spreads: by virtue of that "they attain to an intersubjective objectivity in which 
they can show themselves to numerous subjects of consciousness" (2016, 201). All these activities that aim to fashion their objects into lasting objective entities are "not so free as the acts of free fantasy", they have to take account the peculiarities of material that serve as existential foundations, and this adaptation to material reality is also that allows the historical continuity of the cultural created worlds.

But, to say that men produce objects, tools and cultures, may be seen as a simple, elementary factual observation, which is more a matter of anthropology and archaeology than of ontology. We will therefore ask: why is this relevant to the Idealism-Realism controversy? Yet Ingarden notes on more than one occasion that "the role of man and culture in the world involves an issue that is closely linked to the heart of our controversy" $(2016,614)$.

What is the link? How do culture and cultural objects contribute to the controversy? Precisely because the factual existence of cultural worlds constitutes an authentic problem, and an ontological problem, as the conditions of possibility of their existence are themselves problematic. Indeed, they are only intentional formations (Gebilde) entirely produced by acts of consciousness. It is therefore not clear how these formations can take place in the real material world since the sphere of intentional beings does not share at all the same mode of being as the sphere of autonomous real beings. From a strictly logical and ontological point of view, these two areas cannot be linked. This is also why Ingarden constantly reminds us of the weakness of the intentional aim: it is without force (kraftlos, machtlos), without grip, without any real effect on real things.

It is rather also completely powerless, it is of itself incapable of doing anything with the given, transcendent object (...) the object remains nonetheless outside the scope of the intentional meaning contained in the perceiving. $(2016,196)$

As early as 1925, he noted that "no act of conscience, as such, can, by means of the intention contained in it, "bite" (to speak as H. Conrad-Martius [eingreifen]) on the real unfolding of the objective being and provoke any change therein" $(2007,173)$. The real object is thus really out of reach of the intentional sphere. Only the body, actions and physical behaviours participating in the same sphere of reality could have an impact on things. The means to hit the object realiter "would themselves have to be transcendent vis-à-vis consciousness and fall into the same domain of being as the perceived object" $(2016,196)$. But how can bodily actions respond to such complex intentional objectives as a cathedral or a nuclear power plant? However, these cultural productions do exist. Let's see how Ingarden manages this mystery. 


\section{Cultural world and natural world: what relations?}

The mystery is particularly thickened in Little texts on man. These are texts written at various periods of Ingarden's thought and which were collected in a Polish edition in 1972. This includes The Man and His Reality (1939), The Man and Nature (1958) and The Human Nature (1961). In these texts, Ingarden constantly says that man tests his ontological difference, his strangeness to the natural world, that he does not recognize himself in nature, that he is not at home there. He considers that this inadequacy which would have led men to dominate, develop and transform nature to inhabit a human world, whether through agriculture, technology or works of art.

He creates for himself, a new world, a new reality around and within himself. He creates the world of culture and endows himself with the aspect of humanity. $(1983,18)$.

He creates a human world that is designed, enriched, endowed with the multiple things invented by human creativity. A human world that manifests aesthetic, moral and intellectual values. All these creations contribute to "go into making up the world in which we live and with which we comport daily" $(1983,27)$.

This observation gives rise to complex remarks that insist on the transformation of man himself, because Ingarden underlines that if all these intentional objects transform the natural world by inserting themselves into it, they also have a real action on man. Ingarden insists on this reciprocity of producer and product, thus finding the Hegelian thesis that man is formed by modifying nature, he becomes human by creating the human world in which only he can live. Thus, all the products of art and technology produce us in return:

We ourselves change under the influence of having to do with this (according to some) quasi-reality; we are shaped by it, we acquire new character traits, new likes or dislikes...this world surrounds and influences us, moulding our body, our thoughts, feelings and desires, before we begin to transform it and augment it with new works. It makes us into the heirs of past generations; it is owing to it...that we have a common world of the products of mind (and of the bodily functions that are guided by it)...And when, in turn, we become creators or co-creators of new works of art, new laws, new social or moral ideals, new history, new machines and devices, all this - as if in a backlash - returns to affect us. We live in a different world as a result, and we ourselves are different. $(1983,28)$. 
All these quasi-realities "deeply modify his spiritual life and also, to some extent his corporeal life" $(1983,20)$. Ingarden thus underlines the double transformation of men that is taking place. At the psychological level, access to culture, science and values builds and affirms the dignity of humanity. On the physical level, the body is transformed on different degrees. With trains and planes, we are less robust, we no longer know how to walk as our ancestors did, but we also develop new skills in return: writing, drawing or dancing. Let us think today of the prospects opened up by transhumanism and we can measure with some concern the accuracy of Ingarden's thesis.

Therefore, this anthropological observation leads Ingarden to explore the causal relationships and interactions that take place between autonomous individual objects in the same real world. Here again, Ingarden is resolutely anticipating what is now called anthropocene perspective, namely that human activity has a decisive and lasting impact on the entire environment to the point of creating changes even in physical processes, such as climate, or biological processes, such as the adaptation of some living things (everyone can see for example that squirrels no longer hibernate and stay all winter in urban parks where they find food). Without suspecting such decisive impacts, Ingarden is nevertheless, since the forties (and it is necessary to underline here the acuity of his intuition), able to think of reciprocal relationships of influence and conditioning of objects within the same world, and this question offers a similar character to the fundamental question that concerns us, namely: how can an autonomous object exist in a world where relationships of influence, causality and conditioning are exercised? Therefore, how can new beings introduce themselves into such a world of causal connection?

In $\S 70$ of Der Streit, these questions give rise to ecological considerations (in the systemic sense of the term) about the climate and the new properties that an object can acquire because of environmental changes in its environment. Ingarden takes the example of ecosystems such as the forest or the sea where the interplay of many factors (soil, chemical elements, climate, lights, plants, insects, bacteria) makes everything linked and interdependent. "The forest constitutes a peculiarly structured ecological whole that sustains in itself in equilibrium for a relatively long time" $(2016,582)$. This is what gives to the real world its intimate cohesion $(2016,583)$, and its singular unity which rests both on the need for causal connections but also on a certain chaos, says Ingarden, a certain floating that comes from the potential mutability of individual objects. For if the sets of causal connections make possible in-depth transformations, these transformations must nevertheless be in accordance with the essence of the concerned individual objects, and that is why we must think of a mode of real being that is both determined by the constitutive nature,

\section{8}

Bull. anal. phén. XVI 4 (2020)

https://popups.uliege.be/1782-2041/ @ 2020 ULiège BAP 
and consequently relatively closed, but at the same time a mode of being open and receptive (Empfindlichkeit, 2016, 552) or permeable to its environment. This situation applies to all individual real objects within the world that are time-dependent and exposed to all causal connections in their environment. Ingarden can then note that no being derives all its properties from its own background, no one exists without being influenced, no one is indestructible $(2016,546,552)$. This observation obviously also applies to man as a psychophysical individual being, to whom we must attribute the same porosity as to open and receptive organisms as well as a certain enclosure resulting from its constitutive nature. Man constitutes what Ingarden calls a relatively isolated system.

Variations in interaction processes (between openness and closure) then allow the appearance or the destruction of new properties, qualities and objects $(2016,587)$ by the means of accidents or encounters (Zusammentreffen) in the course of causal connections allowed by the open and inexact nature of the individuals' essence. The causal processes induce a stock of empirical possibilities which, depending on the circumstances and frequency of the repetition, may be realized, altered or aborted. For example, we can evoke "the new shape imposed on the material owing to which it becomes a tool" $(2016,592)$, or the disappearance of plants and animal species such as the appearance and proliferation of green algae in Brittany.

These manifolds of causal connections form such a dense network that nothing can penetrate into its realm without from that instant onward an entirely new manifold of these connections thereby having been realized. $(2016,583)$.

These analyses allow Ingarden to elucidate the situation of processes and transformations in the real autonomous material world. But when it comes about to the creation of cultural works, the problem remains unresolved because it is a question of the relationship of influence and of interaction between two distinct ontological spheres, the real and the intentional. How is that possible?

Ingarden says that transformations can be explained either by "purely worldly factors", either by "extra worldly factors" $(2016,587)$. But engaging in such factual analyses would imply to examine the causal structures of the world, in other words, to engage in metaphysical considerations, and thus to move beyond the ontological-formal plan alone; something Ingarden did not have time to risk. That is why he does not directly respond to what is the core of the problem, but he adds a second problem by considering that the cultural worlds created by human activity are only intentional worlds, only shadows or semblances of reality $(1983,19)$. The question then is inevitably:

9

Bull. anal. phén. XVI 4 (2020)

https://popups.uliege.be/1782-2041/ @ 2020 ULiège BAP 
What, in final philosophical reckoning, are all these strange objects which somehow go into making up the world man lives in: are they reality or fiction? $(1983,28)$.

If we would be quick to decide in favour of their reality, Ingarden nevertheless stresses the ontological fragility of these creations, which depend only on the will of men. The intentional creativity is not able of giving this new world an autonomous existence. "The creative power with which man creates a specifically human world is not unbounded" $(1983,19)$. This is why, strictly speaking, our cultural world, whatever its longevity, does not participate in the autonomous reality of nature even if it is founded on it.

Nevertheless, this world we have created is the true ontological place of our existence: we have lived in continuity in there for centuries. Ingarden well agrees with that: "It cannot be denied that all the objects just enumerated [works of art, buildings, the Polish State, etc.] do exist in some fashion, and go into making up the world in which we live" $(1983,27)$. And he even suggests that this new world built on the basis of nature is more real for man than the real natural world:

He realizes the values of good and beauty, which do, to be sure, appear in merely intentional works, but which at bottom have for him a higher reality than the world of sheer nature. And man remains in the service of realizing these values. When he has managed this, he rests assured in his soul that he does not live in vain. $(1983,20)$.

We understand that in the strictly ontological sense of mode of being, our world is only a semblance of reality: "The product of culture created by man are nothing more than a certain sort of shadow of reality, in that they are merely intentional formations [Gebilde]" $(1983,19)$. But in an existential sense it is our world, no matter how fragile it is. How then can we envisage interactions between the intentional sphere of consciousness and the real sphere in such a way as to consider our world in its consistency, failing an autonomous reality?

\section{One world or two intertwined worlds?}

Ingarden is well aware that the products of human creativity, however intentional and heteronomous they may be, "intertwine in manifolds ways with certain elements of the real world" and he says: "This is no accident" $(2016,611)$.

This intertwining takes place at the level of the physical foundations that anchor the works in reality, and at the psycho-physical level of the willing 
actions of the creators who shape the tools or even make the materials required to embody their visions. There is therefore a phenomenon of intertwining (Verflechtung) between the two domains and in the $\S 74$ of Der Streit, he seeks to clarify the modalities. Ingarden first reminds us that causal connections only exist within the same world $(2016,616)$ and that if we are talking about two areas that intertwine on certain points, it is only because in reality there is only one of them:

If in some other respects it appears that we are dealing with two domains, then as soon as it turns out that their elements intertwine we have to concede that $d e$ facto, it is only one domain. $(2016,614)$.

Intertwining is properly understandable only for homogeneous domains. So, what about the interaction of two different domains? Ingarden states:

No causal connection can obtain between elements of two object-domains, one of which is an autonomously existing world, whereas the other contains exclusively heteronomous - and in particular, purely intentional - entities, since such connections can only occur within the framework of one world. If the existence of such connections were admitted, we would also have to accept that the domain of purely intentional entities would simply fit into the composition of the autonomous world. Then the phenomenon of intertwining between the autonomous and the purely intentional entities (e.g. works of art) would occur within the framework of one world and would also precisely therewith not imply any danger to the self-sufficiency of this world. $(2016,621)$.

Ingarden seems to be suggesting that there can only exist one world, the natural real world, in which man, a real psycho-physical person, manages to find a home and where he inserts new material and cultural realities, works of art, tools as well as values.

\section{Works and things}

Should we then consider that the cultural world produced by the intentional activity of consciousness can be resolved to materialistic explanations, even to a physicalist monism, reducing the intentional works and formations, either to real physical objects or to real mental objects? $(2016,615)$. Ingarden cannot accept this, nor can he accept the opposite transcendental perspective that would treat all cultural things and the world (real and intentional) as products of consciousness. Even if the ontological point of view does not allow us to 
decide anything, we could still be inclined to say that the most credible hypothesis and the most consistent one with the laws of connection of domains is that the realization of the cultural world is based primarily on physical constructions, on the concrete shaping of things, places and materials. And Ingarden largely insists on the fact that the production of our world is first and foremost a material production of things, goods, tools, buildings, houses, bridges, castles, etc. All this presupposes proportional bodily activities, multiplied by the production of the required tools they have developed themselves. In this way, the world of works is also a world of things, as well as a symbolic and significant world.

As Ingarden says, what comes out of an artist's hands is first of all one thing: "what issues directly from the hands of the artist as product of his real (physical) activity is precisely the physical foundation of the work of art in which the latter manifests itself and in which it is fixed" $(2016,622)$. Conversely, the one who destroys a work of art, and with it the values it embodies and exemplifies, destroys only one thing: "some real objectivity qua ontic fundament for some definite value which has been made concrete" $(1983,112)$, because "a value is never something that exists for itself, but it is always the value of something; there is no value whatever which would exist without that something of which it is a value" $(1983,137-138)$. Likewise, the impact of a work of art on the consciousness of a spectator always entails the intervention of a physical medium: the painting, the marble, the acoustic sound of the instruments, etc. Whenever we deal with an idea, a meaning or a value, these socalled intentional objects are embodied, deposited in a physical medium through which they announce themselves and can be grasped by many persons $(2016,622)$. In this respect, since we must always return to the creator's bodily activity, to the physical foundation, to material media, the materialist hypothesis is not so aberrant as it may seem, and in sum, there are multiple sets of causal connections that reflect the interactions between actions, experiences and productions, as the cognitive sciences can consider today.

Nevertheless, Ingarden considers that this is a superficial view (2016, 624), because even if one can have the impression that there are only causal connections, this is not enough to explain the phenomenal presence of cultural objects and especially their impact on people. Indeed, in this case, there are other types of connections, particular existential connections. But it is clear that the created works, even material and massive as a cathedral, do not belong to the real world like the organisms or particles that are part of the world's natural network, and that the real world doesn't spread within them. There is no causal unit, no generic relationship, but "a certain case of existential relations between an intentionally derivative object and one that is more primal - 
i.e. the author himself - and that produces that object intentionally" (2016, 625). It is an intentional connection and not a causal one. Better still, it is an intentional correlation that links the two domains of objects, the real world and the domain of cultural works. Correlation that allows the manufactured thing to bring to light a meaning, a value or an aesthetic object, for a spectator who will be able to reactivate the same intentional acts as the creator from this medium (Träger).

Hence the work of art does not belong to the composition of the real world, but is only correlated to it precisely by means of the phenomenon of intertwining. The intertwining itself, incidentally, is also not real, but merely intentional which is not to say however that it is entirely fictitious or illusory. $(2016,625)$.

The problem reappears as follows: how can we think of this intentional correlation, this correspondence without efficient causal action or without physical causality? Ingarden points out that philosophy has already been illustrated by theories proposing non-causal connections $(2016,617)$. This is the case with the Platonic metexis, the Plotinian emanation, Malebranche's occasionalism or the Leibnizian interexpression, but Ingarden does not retain any of these paths. However, he focuses on the phenomenon of expression (Ausdruck). To say that a face expresses joy is already entering into a non-causal intertwining relationship. Indeed, even if joy seems to appear "within the same world in which physical processes and material exist" $(2016,618)$, in reality, the spatial arrangement of facial features means nothing in itself. It simply refers to, or corresponds, or is correlated to a certain state of mind. Moreover, this state of mind is defined differently according to cultural conventions - a smile doesn't have the same sense in different cultures. The mobility of the face therefore plays an only intentional, and not causal, role of presentation, because these features only make sense for the one who knows how to actualize the correlative operations of consciousness. Likewise, and by extension, any shaped or manufactured thing is endowed with an expressive capacity or an appearance function (zur-Schau-bringen), but this does not causally combine the two domains, which remain mysteriously juxtaposed in their duality.

This reality [created by men] is only a certain stratum intentionally created and, as it were, laid over the substratum of real nature. $(1983,23)$.

Consequently, and strictly speaking, the very notion of intertwining is inaccurate. And it must undoubtedly be agreed, as Ingarden suggests at the beginning of $\S 74$, that we are only dealing with a phenomenon (Phänomen), i.e. an ap- 
pearance of interlacing or quasi-interlacing. But, in fine, as Ingarden often reminds us: "we cannot assert at this stage of the deliberation that there is actually the fact of intertwining" $(2016,614)$. We must only confine ourselves to the ontological order of possibilities. However, the Little texts on man suggest positions on what Ingarden seems to believe on the human and existential level and that he forbids himself to think on the ontological-formal level. On the basis of these few indications, I propose some suggestions to try to situate Ingarden's position between realism and idealism.

\section{Standing on the border}

In the absence of real intertwining, Ingarden seems to invite us to a new approach: to think of the border, that is, to think together both parts of the duality that punctually accepts the encounter. We can even go so far as to evoke a kind of dialectics, with all the reservations that must be accepted for this notion in a structural conception like Ingarden's. Ingarden's invitation to think along the meanders of a border line is explicit in his own text. Thus, he wrote in 1958, in Man \& nature:

Man exists and lives on the boundary of two essences, only one of which seems to comprise his humanity, and the other - unfortunately more real than the first, so to speak - stems from his animality and conditions the first. Man finds himself on the boundary of two regions of being: nature and the specifically human world. $(1983,20)$.

Similarly, in Der Streit, he indicates that the existence of man is revealed "on the borderline between the sphere of what is consciousness-like and the sphere of the transcendence of my body (and of my mind)" $(2016,187)$. The process of perception itself is sufficient to make us understand it because perception consists in standing on the dividing line between the immanent and the transcendent, articulating like Janus' two faces: the purely conscious intending and "the collaboration of the sense organs" $(2016,188)$. The same is true of the work of artistic creation or technical production, which show us this same duality, retaining in the juxtaposition of a kind of crochet the two orders of reality:

These products of human culture are constituted on the basis of the things and the processes of the natural world and are made suitable for that end by man; 
and the properties of the former surpass the bounds of qualitative endowment of material things covering them with a new layer of senses and new phenomena. $(1983,19)$.

\section{What kinds of Realism?}

In this context, what can we say about the realism Ingarden claims? What kind of ambiguous or ambivalent realism does Ingarden adhere to?

First of all, on the ontological level, we can speak about a naturalistic realism, in which physical causality plays a major role, even if it can be balanced by chaotic floating movements between the various networks of connections. In this context, Ingarden places man on an equal position with other organic beings, while emphasizing that he dislikes this animal origin and that he continuously fights it through the creation of cultural works. Despite this, he remains a psycho-physical animal that cannot escape the various physicchemical processes that take place within and outside him. In this way, Ingarden doesn't agree with any dualism, nor separation between the soul and the body. "Every human being is a corporeal and psychic being" $(1983,78)$. This is why he denies, against Husserl, the distinct existence of a pure ego that would be added in some way to the real personal self, because a pure ego cannot act; only the whole person with his qualities and habits really incorporated in his body and soul can act in the real world because she is a part of it. In this sense there is a physical or organic continuity of the person from the skeleton to the "threshold of consciousness (as a special constituent part within the brain)" (1983, 95). So, we can assume a naturalistic realism that links all things and beings in the real world under the same mode of being real.

As a second point, it is a realism that considers the transcendence and exteriority of things as an indication of their ontological autonomy and independence, that is what he calls transcendence 1 . In this respect, he refuses to reduce things to their be-perceived potential (1918), and speculates on qualities that could be "silent", that is, avoid the possibility of being grasped in the experience (1929, 50 [Erfahrbarkeit], 2001, 194-96). But this realism does not go so far as to admit the possibility of a reality that would be absolutely unknowable and foreign to man as the thing-in-itself Kantian. He says it explicitly in his commentary on the Krisis where he states: "It is only transcendence in the sense that it means something that is absolutely unknowable (such as Kant's thing-in-itself) that I reject in agreement with Husserl.” $(1969,446)$. In this respect, it can be considered that it supports a relatively moderate realism. And in somehow, this moderate realism can define also the intentional objects, 
because if they are irreal as products of intentional acts, they are nevertheless consistent and transcendent to the acts, they also can be intended and shared by many people. That is what Ingarden calls transcendence 2 , that is transcendence in the immanence of the conscious acts. That transcendence may be strengthened when the object can have foundation in re, and foundation in ideal objects or concepts, so that the intentional object is in a middle way between real world, conscious sphere and ideal beings. In this double sense, we can admit a moderate realism.

But Ingarden is also ambiguous, because he is very well disposed to an epistemological idealism. As I mentioned above, Ingarden considers that "There is no idealism in affirming that the phenomena/noema that reveal objects to us are constituted by cognitive processes". In the same sense, the multiple intentional attitudes he describes (for example in front of the building and the architectural work $(1945,262)$, which mean that one never refers to things in a raw or passive way but always already according to the mediation of a certain intentional meaning) remain largely in agreement with Husserlian idealism according to which nothing is given that is not first constituted by an intentional meaning. On this point, the analyses of the original data in $\S 46$ of Der Streit $(2016,180)$ as well as the Lessons on the objectivity of external perception $(1926,87)$ are also instructive, because Ingarden admits that there are modifications of the data since the initial retention level. It involves that data become quasi-data, in other words, that they become a kind of intentional meaning as soon as this original level. We can thus measure that the distinction between ontological realism and epistemological idealism is very delicate, and here again we remain on a kind of border.

To this ambivalence, we must finally add the metaphysic realism of ideas and ideal qualities, since these are so many objects that would form an absolute autonomous sphere of being. For Ingarden, the use of eidetic intuition has been required since 1918 as a legitimate methodology for exploring the content of ideas. Intuition (der intuitiven Erschauung) serves as a guiding thread for ontological research. And in the field of values, for example, he still says in 1963:

Nothing can free us from the scientific task of exercising the intuitive vision of the specificity of values, as well as the spiritual effort linked to it. (1969a, 103).

But, that doesn't mean that value are ideal objects. And finally, about values, both aesthetic and moral to the extent, Ingarden is always very cautious, not to say undecided. He notes that values are always inseparable from what they are the value of and in which they are embodied. In this sense, one could say they 
are not objects that exist in themselves. But Ingarden makes also allusive remarks noting in the margin of the text: "Beside the concretized values, there are also the ideal value entities [Wertwesenheiten] as well as the general ideas of values [Ideen der Werte]. These latter are outside of the real world." (1983, 117 , note 45). It remains ambiguous because ideas of values are not the same as ideal values, and that doesn't imply that there actually are values. Finally, in his Ethics course of March 13, 1962, he states:

Values are neither real in the sense that the electric current is real [...] nor in the sense that anger or wonder are real [...]. It is necessary to look here for a middle way, a certain distinct existentiae modus, which would be on the one hand something other than mere reality and on the other something more than mere intentionality. (1989, 337).

This ambivalent position is constant in Ingarden's work and, consequently, it raises questions about his ever-repeated desire to counter Husserlian idealism, since at the same time he maintains the same strong opposition to all kinds of scientism, reductionism and relativism. That is why, by focusing above all on the question of values, I think we could talk about emergence and consider a kind of emergence realism.

\section{Emergence and supervenient qualities}

If we remember the results of The Literary Work of Art, the last part deals with the metaphysical qualities of the work of art, such as the sublime, the marvellous or the tragic. These, says Ingarden, are derived qualities that emerge in a way from the polyphonic harmony that the different strata of the work manage to achieve. The different strata interact and give rise to something that goes beyond the artist's only intentional project. This is also why the work gives the feeling of a reality that escapes and then offers a density comparable to that of natural real things, as if it formed an organic unity. Similarly, with regard to moral, religious or affective values, Ingarden indicates that these "values emerge only on that superimposed reality we have created" and "these values become manifest through that reality or demand its creation for their embodiment" $(1983,29-30)$.

This notion of emergence seems to me to be relevant to Ingarden's philosophy because, from Das literarische Kunstwerk to texts on values and via Der Streit, Ingarden never stops using a concept that he applies very broadly, 
that of Gestalt and of Gestaltqualität. He adopts these notions from the philosopher Christian Von Ehrenfels who founded Gestalt psychology in 1890. From musical examples, he showed that perception is not reduced to the capture of a set of elements but that in listening to a melody, something new appears, something more than the sum of the different successive notes. Proof of this is that one can play the same melody in different tones and yet recognize it, while no note remains identical. The melody thus constitutes a somehow superior and derived entity that emerges when other qualities are co-present. Ingarden embraces this idea of a harmonic unity that is built on the basis of other coexisting qualities. "It only makes its appearance in the presence of others qualities that found it" $(2016,91)$. In other words, the coexistence of several qualities can bring to light something new, both derived and irreducible. It is as if a certain dialectical dynamic managed to bring out meaning, ideas, values and forms from the layered structures of a work.

Ingarden's ontology describes the multiple stratifications of works of arts, but without succeeding in unveiling the mystery of the emergence of new qualities. Thus, perhaps we could explore this concept of emergence based on the notion of Gestalt, and reintroduce a certain form of immanent dialectic into Ingardenian structuralism. Ingarden speaks indeed most often in terms of emergence (erwachsen, hervortreten, heraustreten, auftauchen) and derivation. He speaks also of superstructure (Überbau) as early as 1947 and he will use again the same term in 1965.

A value is always a certain kind of superstructure (Überbau) built up on the basis of that whose value it is. This superstructure...is not something alien in relation of the valued object, it is not thrust upon or added onto it from without, but emanates (erwächst) out of its very essence. $(1983,142)$.

This German term clearly expresses the fact of appearing by going beyond a set of elements that serve as a necessary but not sufficient basis and make possible a certain dynamic that can be grasped by the subject in order to give rise to meaning, qualities, values from neutral properties. The interest of this perspective is that it makes it possible to consider both continuity and rupture between the order of fact and that of values. On the basis of neutral features or properties $(1985,99)$, values emerge that constitute new aspects and are not causally deduced from the elements that serve as their basis. To argue in this sense, it seems justifiable to bring Ingarden's ontological analyses closer to the more contemporary theories of aesthetic supervenience or supervenient qualities. Contemporary philosophers such as Curie (1989), Pettit (1983), Zemach 
(1992) or Pouivet (2010) defend aesthetic conceptions relatively close to Ingarden's perspective.

The notion of supervenience was first introduced by the philosopher Donald Davidson to account for both the dependence and the irreducibility of mental states in relation to the bodily or neurological states on which they are based. The principle is based on the idea that there can be dependency and covariation relationships between lower-level properties and higher-level properties. Thus, a property B may arise on the basis of a property A, if it is ontologically dependent on it and co-varies with A (i.e. any change in A leads to changes in $\mathrm{B}$, but without reciprocity), and if $\mathrm{B}$ is not reducible nor analytically deductible from $\mathrm{A}$. The whole point of this theory is that the derived or supervenient properties stand in a relationship of dependence on the properties that serve as basis or foundation, as Ingarden would say, but in a dependence that is neither univocal nor necessary. The relationship of dependence accepts variation and contingency, while being an objective foundation in the thing itself. In Ingardenian terms, that means that an aesthetic quality has an objective basis in material quality determinations anchored in the properties of the object to which it belongs and yet it is irreducible to these properties alone. This is actually the mode of appearance of Gestalt and Gestalt-qualities.

However, it is important to stress that this emergence or supervenience of qualities through the Gestalt model does not imply a causal relationship. As Roger Pouivet explicitly reminds us, "the notion of supervenience is not causal, otherwise there would be aesthetic laws on the model of natural laws". The theory of supervenience "offers only a plausible description of the logical relationship that this emergence implies" $(2010,160)$. It is not possible to explain why and according to what causes such aesthetic properties occur. This remark is very important because sometime we could get the feeling that Ingarden is looking for a more radical, possibly causal and at the very least real foundation. Yet, the different interacting factors (subjective and objective) cannot operate in a homogeneous and systematic manner. There are many circumstances of variability and contingency in the reception of spectators that induce unpredictable variations. Ingarden knows this very well:

That very (alleged) 'springing or issuing forth' of values out of these particular relations is a quite obscure issue. For it seems to be neither the consequence of a logical inference (logisches Sich-Ergeben), nor something like a causal elicitation of an effect [ursächliches Hervorgehen]. What type could it be? (1983, 140). 
Neither purely causal, nor purely intentional, the founding regime of the emergence or of the supervenience of qualities and values remains difficult to define. And the difficulty has repercussions on the mode of being of these qualities, which remains undecidable:

It seems that no form or variant of mode of being that is familiar to us (thus, neither ideal being, nor real being, nor purely intentional being (heteronomous being) is fit to be ascribed to the way in which at least some values exist. (1983, 149).

It's so complex that Ingarden even considers the possibility of completely new modes of being:

It also seems that in the diverse modes of being that we encounter in the domain of value we have to do with new modes of existence in comparison with those I have tried to circumscribe in volume 1 [§33] of Streit. $(1983,151)$.

Whatever the mode of being of values, what remains imperative for Ingarden is that values could be credited with a mode of reality or consistency such that any relativistic drift can be avoided. That is why it is necessary to clarify their foundation, hoping to reach an objective foundation that guarantees their transcendence, as strongly as that of autonomous real things. It is in this sense that Ingarden's realism once again imposes itself, even if it is difficult to qualify it.

Derived, heteronomous, emergent but non-separable, values and qualities are about a mode of appearance that is not causal but intentional and yet it also involves factual circumstances and foundations which stand in the real world. This emergence makes it possible to pass from the real world to the intentional world, not through a real intertwining but through something like a crossing of borders, a mysterious exchange between the two domains of being. Similarly, when dealing with the immense problem of responsibility, Ingarden begins by placing man in the nature and in his body in order to locate the different exchanges between organ and function systems. It is important for him to show that there are causal crossovers between open systems but that there are also systems (relatively isolated systems) that do not enter into a causal relationship while being located at the same time. This requires thinking of effects, both dependent and partially independent of a higher system:

Various complicated situations can emerge in the causal conditionedness of an event. There is not even excluded that the causation of an event within the interior of a supersystem lies entirely outside its domain, as, for example, when two processes break into the supersystem and intersect in its interior but which

20

Bull. anal. phén. XVI 4 (2020)

https://popups.uliege.be/1782-2041/ @ 2020 ULiège BAP 
themselves have their initial events and perhaps their causes outside of the given supersystem. $(1983,105)$

The notion of an open system is a notion that seems favourable to him and that offers interesting conceptual possibilities. He refers to the biologist Bertalanffy for this, but he quickly distinguishes himself from him because he is aware that they do not share the same philosophical problem:

By the system's 'openness' he understands only its allowing exchange of material with the surrounding world, whereas my concern is primarily with the possibility of a penetration of causal processes through the boundaries of the system. $(1983,115$, note 25$)$.

Crossing borders, producing and inserting new objects or properties into the causal order of things, being subject to the natural laws of the world and yet also being able to act in a distinct and new way - these are possibilities that Ingarden hopes to clarify in order to make comprehensible human life and the creation of cultural objects and worlds. The conception of man as a relatively isolated system makes possible a certain idea of freedom and responsibility. Indeed, as an open, permeable and at the same time isolated system, man can realize actions "which are his own, actions which are independent of the external world, however much this action is, within the human being himself, causally conditioned" $(1983,100)$. One can then both think of the world as a system of causal connections in which man is a part subject to the various causal games and, at the same time, one can think of actions that cross borders. Naturalist realism can thus potentially articulate with the irruption of intentional creations through the emergence of qualities, values, and perhaps more radically, of conscious life itself.

\section{Conclusion}

The analysis of intentional objects as well as the analysis of the place of man and cultural objects in the world is at the heart of the Idealism-Realism controversy. Indeed, understanding how intentional quasi-realities manage to fit into the system of causal connections in the real world, this requires clarification of whether and how natural causal relationships are compatible with the appearance of new properties or objects within the same world. It therefore requires thinking about the intertwining of the two modes of being that are the intentional sphere and natural reality. The possibility of such an intertwining would make it possible to satisfy the claim of realism that Ingarden promotes 
since the letter of 1918, a realism based on a fundamental opposition between the subjective and the objective. As the real is what resists consciousness, the whole problem of the Ingardenian philosophy consists in determining those objectivities which are consistent, opposed to consciousness and which do not always offer the same mode of being:

a) the natural and material objectivity of things, bodies and man himself as an organism, which corresponds to the realism of transcendence I,

b) the ideal objectivity of ideal qualities, objects and concepts, which induces a metaphysical realism that remains relatively mysterious,

c) the objectivity of the intentional meanings based on ideal concepts. This corresponds to the transcendence of noema in the immanence of lived experience (transcendence II) and that supports a certain epistemological idealism, because access to things themselves remains mediated by intentional meaning,

d) this objectivity of meaning and intentional products can lead to an inter-subjective cultural reality (cultural realism) when it finds foundations in $r e$ that guarantee to its products diffusion, sharing and longevity,

e) the objectivity of values is required to make human actions meaningful and responsible, but the perplexity induced by their mode of being opens up the possibility of understanding them in terms of supervenient qualities. This theory has the advantage of maintaining the unity and continuity of interactions and forms of causality in the natural system of the real world through the assumption that systems are both open and relatively isolated within a single world.

In these different cases, Ingarden keeps the line of a naturalistic realism coupled with the realism of the essences.

Traversing borders, crossing boundaries seems to be expressions that sound as close as possible to Ingarden's conceptions: human lives and thoughts are destined to move, to meander between the real world and the intentional world, between the system of consciousness and that of natural connections, while letting itself be inspired and guided by values that are both created and discovered. Isn't it an invitation to think of a realism, even a naturalism, that would make possible the emergence of intentional life? If the heterogeneity of essence between consciousness and the world could have been derived from the coexistence of worldly qualities, so we can think in return that intentional creations could find a place in the world, for precisely they are proceeding from them in some way. Such a perspective would not concede to any reductionism nor scientism. 


\section{Bibliography}

AA. VV. (1959). Husserl. Cahiers de Royaumont. Philosophie III. Paris: Minuit. Chrudzimski, A. (Ed.). (2005). Existence, Culture, Persons. The Ontology of Roman Ingarden. Frankfurt, Ontos Verlag.

Curie, G. (1989). An Ontology of Art. London, MacMillan Press.

Husserl, E. (1913). Ideen zu einer reinen Phänomenologie und phänomenologischen Philosophie. In Jahrbuch für Philosophie und phänomenologische Forschung, Vol. 1. Halle: Max Niemeyer Verlag.

Ingarden, R. (1918). "Der Brief an Husserl über die VI. Untersuchung und den Idealismus". In Schriften zur Phänomenologie Edmund Husserls. Gesammelte Werke, Vol. 5. Tübingen: Max Niemeyer Verlag (1998). 1-20.

- (1976). "The Letter to Husserl about the VI [Logical] Investigation and Idealism", published in Analecta Husserliana 4.

- (1925). "Essentiale Fragen. Ein Beitrag zum Wesensproblem". Jahrbuch für Philosophie und phänomenologische Forschung 7. 125-304. New edition in Ingarden, R. (2007). Über das Wesen. Peter McCormick (Ed.). Universitätsverlag Heidelberg. 1-192.

— (1926). "Zum Problem des Objektivität des äußeren Wahrnehmung (Lemberger Vorlesungen, 1926-27)". In Zur Objektivität der sinnlichen Wahrnehmung. Gesammelte Werke, Vol. 8. Tübingen: Max Niemeyer Verlag (1997).

- (1929). "Bemerkungen zum Problem Idealismus-Realismus". In Schriften zur Phänomenologie Edmund Husserls. Gesammelte Werke, Vol. 5. Tübingen: Max Niemeyer Verlag (1998) 21-54.

- (1945) "Das Werk der Architektur", in Untersuchungen zur Ontologie der Kunst. Tübingen: Niemeyer Verlag (1962). 257-315.

— (1956). "Über den transzendentalen Idealismus bei E. Husserl". Phaenomenologica 2. Den Haag: Nijhoff (1959) 190-204.

- (1959). "Le problème de la constitution et le sens de la réflexion constitutive chez Edmund Husserl". In Husserl, Cahiers de Royaumont. Philosophie III. Paris: Minuit (243-264).

- (1963). "Über die Motive, die Husserl zum transzendentalen Idealismus geführt habe". In Schriften zur Phänomenologie Edmund Husserls. Gesammelte Werke, Vol. 5. Tübingen: Max Niemeyer Verlag (1998) 274-351.

- (1964). Der Streit um die Existenz der Welt. Vol. 1 : Existenzialontologie. Tübingen: Max Niemeyer Verlag. (2013) Controversy over the existence of the world. English translation by A. Szylewicz. Peter Lang Edition.

- (1965 a). Der Streit um die Existenz der Welt. Vol. 2/1, Formalontologie. Part 1: Form und Wesen. Tübingen: Max Niemeyer Verlag.

— (1965 b). Der Streit um die Existenz der Welt. Vol. 2/2, Formalontologie. Part 2: Welt und Bewußtsein. Tübingen: Max Niemeyer Verlag. (2016) Controversy over the existence of the world, Formalontologie. Part. $1 \& 2$. English translation by A. Szylewicz. Peter Lang Edition. 
- (1967). Osloer Vorlesungen. In Einführung in die Phänomenologie Edmund Husserls. Gesammelte Werke. Vol. 4. Tübingen: Max Niemeyer Verlag. 1992.

- (1969 a) Erlebnis, Kunstwerk und Wert. Vorträge zur Ästhetik, 1937-1967. Tübingen, Niemeyer Darmstadt, Wissenschaftliche Buchgesellschaft.

— (1969 b). "Was gibt es Neues in Husserls Krisis?” In Schriften zur Phänomenologie Edmund Husserls. Gesammelte Werke, Vol. 5. Tübingen: Max Niemeyer Verlag (1998) 431-460.

- (1975). “On the Motives which led Husserl to Transcendental Idealism”. Den Haag Martinus Nijhoff, 1975. Series: Phaenomenologica, 64.

- (1983). Man and Value. (A. Szylewicz, Ed.). München: Philosophia Verlag, Washington DC, Catholic University of America Press. Including: Man and Nature, $17-$ 20. On Human Nature, 21-24. Man and his Reality, 25-32. Man and Time, 33-52. On responsibility, Its ontic foundations, 53-118. Remarks on the relativity of Values, 119-130. What we don't know about values, 131-164. An analysis on Moral Values, 165-178.

- (1985). Selected papers in Aesthetics. (Peter J. McCormick, Ed.), München, Philosophia Verlag, Washington DC, Catholic University of America Press.

- (1989). Wyklady z etyki (Cours d'éthique). Varsovie: PWN.

Mitscherling, J. (1997). Roman Ingarden's Ontology and Aesthetics. University of Ottawa, Press.

Limido, P. (2001). Roman Ingarden, Husserl, La querelle idéalisme-réalisme. Paris, Vrin.

Limido, P. (Ed.). (2013). Roman Ingarden. La phénoménologie à la croisée des arts. Rennes, Presses Universitaires de Rennes.

Makota, J. (1990). "Roman Ingarden's Idea of Relatively Isolated Systems", in Ingardeniana II, Analecta Husserliana. USA: Springer, Vol. (30), 211-222.

Malherbe, O., Richard, S. (Eds.). Forme(s) et modes d'être. L'ontologie de Roman Ingarden. Bruxelles, Peter Lang, 2016.

Pettit, P. (1983). “The possibility of aesthetics realism”. In E. Schaper (Ed.). Pleasure, Preference and Value. Cambridge UP.

Pouivet, R. (2010). L'ontologie de l'œuvre d'art. Paris, Vrin.

Réhault, S. (2013). La beauté des choses: esthétique, métaphysique et éthique. Rennes, Presses Universitaires de Rennes.

Rynkiewicz, K. (2008). Zwischen Realismus und Idealismus: Ingardens Überwindung des transzendentalen Idealismus Husserls. Frankfurt, Ontos Verlag.

Schaeffer, J.-M., Potocki, C. (Eds.). (2012). Roman Ingarden: ontologie, esthétique, fiction. Paris, Éditions des archives contemporaines.

Świderski, E. M. (2005). "From phenomenological realism to moral realism". In Chrudzimski, A. (Ed.). Existence, Culture, and Persons. The Ontology of Roman Ingarden. (159-189). Frankfurt, Ontos Verlag.

Świderski, E. M. (2016). “Ingarden's 'Material-Value' Conception of Socio-Cultural Reality”. In Salice A., Schmid H. (Eds). The Phenomenological Approach to Social Reality. Studies in the Philosophy of Sociality. (259-278). Springer. 
Timieniecka, A.-T. (1957). Essence et existence. Essai sur la philosophie de Nicolai Hartmann et Roman Ingarden. Paris, Aubier-Montaigne.

Thomasson, A. (2005). "Ingarden and the Ontology of Cultural Objects". In Chrudzimski, A. (Ed.). Existence, Culture, and Persons. The Ontology of Roman Ingarden. (115-136). Frankfurt, Ontos Verlag.

Zemach, E. (1992). Real Beauty. Pennsylvania State University Press. 